\title{
The Ficus Upshot Model of Reading Development: A Conceptual Analysis
}

\author{
Philomena Chepsiror \\ School of Education, Moi University, P.O Box 3900, Eldoret, Kenya
}

\begin{abstract}
Reading is central to functioning in today's world. Studies have shown that becoming competent readers early in life is one critical pointer of children's academic achievement and success in life. Reading competency is determined by the strategies employed in teaching emergent (early) reading. Studies in early reading proficiency have shown that there is an unswerving correlation between children's competency in reading and their learning outcomes. Success in achieving early reading proficiency is determined by the strategies employed in teaching which centre on the children's enjoyment of reading, motivation to read and confidence in their aptitudes. This paper illustrates a conceptual framework showing how experiential learning strategy which when effectively utilized at the very beginning of the reading continuum, supported by the necessary environments with the proper inputs from the school administration, lays a strong foundation for proficiency in later reading.
\end{abstract}

Key words: Conceptual analysis, Reading, Emergent, strategies, experiential, proficiency.

DOI: $10.7176 / \mathrm{JEP} / 10-30-09$

Publication date:October $31^{\text {st }} 2019$

\section{$1 \quad$ Introdution}

Now, more than ever before, educationalists and policy makers throughout the world are paying unprecedented attention to the quality of education offered for young children. Credible evidence show that early childhood experiences are an important foundation for preparing children for educational itineraries in the highly competitive education system. (Nores and Barnet, 2010, Roopnarine and Johnson, 2013, Wortham and Hardin, 2015).

Globally, incredible consideration has been devoted to reading among young children. This is because studies have shown that becoming competent readers early in life is one critical pointer of children's academic success (Muij and Reynolds (2001) Snow, Burns and Griffins (1998). Musen (2010) confirms that children who cannot read well at this stage will encounter setbacks at school and will seldom reach their potential both at school and in life. Musen proposed that by third grade, learners are expected to know the basics of reading and be able to apply reading skills across the curriculum.

Reading competency is determined by the strategies employed in teaching early reading. The term early reading is often used to explain a child's knowledge of reading and writing skills before they learn to read and write words. The old belief that children must orally be fluent before being introduced to reading and writing still holds. Only after children were exhaustively geared up with necessary pre-reading skills was 'real' reading instruction begun. Research has shown that effective classroom instruction in this skills is the only solution to creating strong, proficient readers. As articulated by Wigfield (2007), success in achieving early reading proficiency centres on the children's enjoyment of reading, motivation to read and confidence in their aptitudes. Terenzi and Pascarella(1994), Rich, Drummond, myer and Dixon (2005) believed that increased learning will occur if teachers use learner centred approach where they utilize the learner's experiences and knowledge in the learning process. They emphasized that young children are expert, intrepid and great explorers of their world and therefore, from an early age, and throughout their school lives, children need to be encouraged to engage with the world, using all their senses in order to fully enjoy all that it has to offer. Kolb (1984) termed this approach to teaching and learning as experiential learning. In its simplest form, experiential learning means learning from experience or learning by doing.

According to Thompson (2008) the word experiential essentially means that learning and development are achieved through personally determined experience and involvement, rather than on received teaching or 
training, typically in group, by observation, listening, study of theory or hypothesis, or some other transfer of skills or knowledge. According to Bartsch (2013), the expression 'hands-on' learning, more commonly known as experiential education, reflects a teaching philosophy that promotes learning by doing. The strategy allows children to practice guided tactile learning in which they absorb knowledge, not only by listening, but by experiences. This was reverberated by the Bureau of elementary education (1994) when it supposed that people of all ages benefit from "hands-on" experiences. By seeing, hearing, touching and exploring the world around them and experiencing challenge and adventure, they find out how what they learn at school relates to their life outside.

One of the principles of good teaching according to Dodd (1994) is to engage the student in his/her own learning. He observes that the most effective teachers reflect on their classroom experience. When a child is seriously interested in what he is doing, he observes everything carefully and becomes familiar with the materials he is using. Although teachers may express their ideas differently, effective teachers know that to become engaged, students must have some feelings of ownership of the class or the task and personal power, a belief that what they do will make a difference.

\section{$2 \quad$ Early Reading Development}

Early reading (also known as emergent reading) has been defined as the point at which a person transits from being a non-reader to a reader. Basic components of emergent literacy includes (Wikipedia): print motivation, vocabulary, print awareness, narrative skills, letter knowledge and phonological_awareness.

Print motivation is a component that relates to a child's interest in and enjoyment of books. A child with print motivation might enjoy being read to, playing with books, pretending to write, and going to the library. Children who enjoy books are more likely to want to read, and to keep trying, even when it is hard. The component "vocabulary" relates to knowing of the names of things. Print awareness is the component that relates to noticing print, knowing how to handle a book, and knowing how to follow words on a page. It includes knowing that words are read from left to right and top to bottom, and how to tell words from letters.

Narrative skills is the factor that relates to the ability to describe things and events and to tell stories. This helps children to vocalize, pronounce and discriminate sounds and words of language. Letter knowledge is the element that has to do with the understanding that letters are different from each other, knowing their names and sounds, and recognizing letters everywhere. Knowledge of the alphabet letters help children learn to name letters and to distinguish them from each other.

Phonological awareness is the part that is connected with being able to hear and play with the smaller sounds in words. It involves rhyme recognition, syllables, awareness of sounds in language, awareness of rhymes and ability to talk about, reflect upon and manipulate sounds. These skills are invaluable to a child's literacy development because without these skills, a child will have difficulty learning how to read and write.

\section{$3 \quad$ The Ficus upshot Model}

The model outlined in Figure 1 reflects an approach to reading that borrows from the ficus tree. Underpinning this framework is the perspective of the engaged child and engaged teaching and learning. In the model, the three most important elements that determine the health of a tree are the roots, the weeds and the fruits. The root systems are vital to the health and longevity of trees. Healthy roots are necessary for the growing success of the tree. In the framework the centre root (Tap root) represents the experiential learning strategies, while the branching roots signify the supporting structures that is environmental features and administrative provisions. The fruits signify the outcomes of the foundation provided for children on reading; proficiency in reading. 


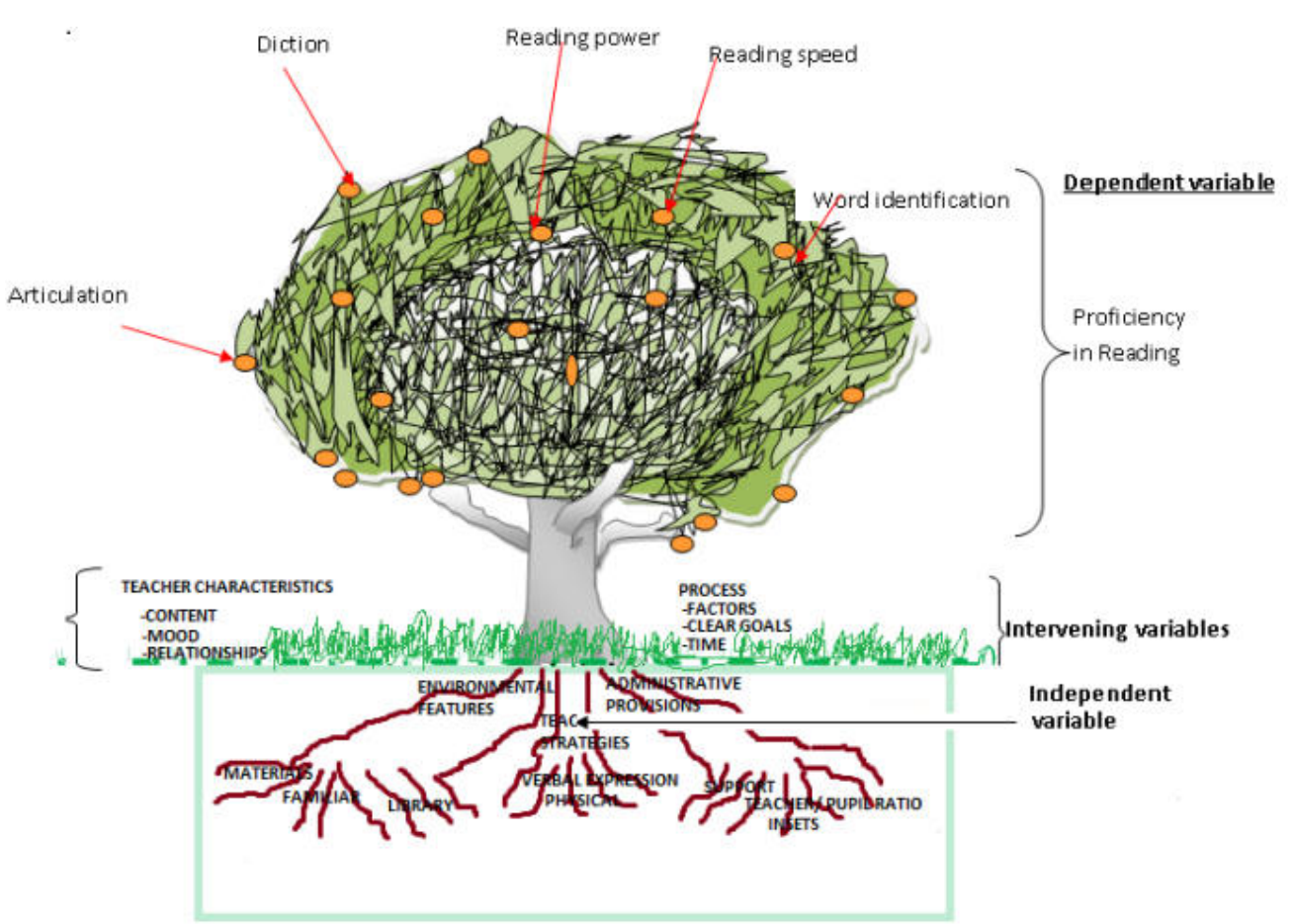

Figure 1: The Ficus Upshot Model of Reading development

\subsection{The independent variable (Learning strategies)}

In his/her career, the goal of every teacher is to develop the individual child's potential abilities to his/her utmost. This can be done by laying a firm foundation for reading through a variety of creative learning experiences. Learning experiences that engage children are especially important during the early years when children's motivation, attitudes and behaviors to learning are developing. According to Miller and Commons (1994) the Experiential learning strategy is a powerful educational vehicle for promoting proficiency in reading and can do so more efficiently than classroom instruction. Classrooms, therefore must provide different experiential strategies to meet individual learner's strength in order to be most successful. Foley et al (2008) also believes that activities at this stage are the ones that determine later success or shortfall in reading. Children must have a direct encounter with what they are learning and take individual liability for their learning. Learning by doing allows children to become personally invested in their learning process. Becoming actively engaged in their learning builds confidence, as lessons require students to rely on their abilities to obtain knowledge. Lessons for reading in the formative stages should therefore be play-based heavily relying on hands-on experiences in the form of physical activity such as block building, reading games, the Graphic Arts, visual expression, critical looking and picture reading; verbal expression, for example dramatic and role play, and other firsthand related activities; supported by settings that sustain literacy activities, skills and strategies. Some suggested experiential learning experiences for early reading are suggested thus:

\subsubsection{Learning through play}

UNESCO (2008) submitted that Early Childhood Development and Education (ECDE) teaching strategies require interaction and play, not rote learning methods. It further stated that young children are active learners who construct their own understanding of the world. Additionally, Crombie (1995) said that preschool learning experiences which promote literacy are deeply embedded in the context of play when well designed, such an approach taps into children's individual interests, draws out their emerging capacities, and responds to their sense of inquiry and exploration of the world around them. It generates highly motivated children enjoying an environment where the learning outcomes of a curriculum are more likely to be achieved" (Pascal (1977). According to Singer and Singer (2010), as children learn through purposive, quality play, they build critical language skills such as verbalization, language comprehension and vocabulary.

\subsubsection{Early reading and the graphic Arts}

Lindberg and Swedlow (1976) assert that graphic arts provide opportunities for motor activities, for expression of feelings, and for the clarification of experience. Children work with crayons, tempera paints, finger painting, 
strings and other materials. Some techniques that can be learnt is that of using scissors for cutting and using a paintbrush, and finger painting. As the child works with these materials, he will talk about what he is drawing or painting or tell stories about it,

\subsubsection{Learning through Music and movement}

Lindberg and Swedlow (1976) believed that young children seem to be naturally "wired" for sound and rhythm. Besides providing enjoyment, music can play an important role in language and literacy development. Teachers should therefore integrate song, dance, rhythm, poetry chants and nursery raps in their lessons. Through music, children are able to imagine new words, pick up the correct pronunciation of words and enhance vocabulary.

\subsubsection{Learning in groups}

As described by UNICEF (1999), when learners work in pairs and small groups, they can engage in communicating ideas, in co-operating to accomplish goals, in peer review of each other's work, and in couching. Children of different abilities can be group together to participate in projects and activities, and to create opportunities for peer mentoring and couching. Children of different abilities may also have different aptitudes and talents, so that one member of a group may assist the others with reading, while another represents the group's work in pictures. Lindberg and Swedlow (1976) assert that when working together, children communicate with each other verbally and nonverbally. As children interact in thrill-seeking activities, vocabularies are extended to meet the situation.

\subsubsection{Promoting early reading through stories}

Linberg and Swedlow (1976) assert that the first books a child is exposed to and the ways in which they are introduced may determine his literacy tastes for a life time. When adults put emphasis on the mechanics of reading before children have an understanding of the value of books, children resist books. When the teacher is excited about books and stories, children become enthusiastic and look forward to hearing stories and looking at books. Books and stories offer children the opportunity to hear new vocabulary items embedded in varied grammatical sentences. Books written for children often use well-formed, relatively short sentences that are rich in varied vocabulary. Furthermore, books often use the same words in diverse grammatical constructions, offering implicit lessons in how words are used.

\subsubsection{Development of early reading through drama}

Baldwin and Fleming (2012) describe drama as a shared and cooperative activity which fires the individual and collective imagination. This may be channeled into form of artistic expression. In make believe or dramatic play children are abstracting from their knowledge of the real world in order to establish for themselves a makebelieve world within which they are empowered to operate and interact effectively. Davidson (1996) claims that dramatic play fosters reading development as it encourages children to use rich, detailed language.

\subsubsection{Promoting early reading through Project}

Katz (1994) describes a project as an in-depth investigation of a topic worth learning more about. The investigation is usually undertaken by a small group of children within a class, sometimes by a whole class, and occasionally by an individual child. The key feature of a project is that it is a research effort deliberately focused on finding answers to questions about a topic posed either by the children, the teacher, or the teacher working with the children. Sandefur, Hicks, Buck, Warren and Gamble (2006) believed that when using the Project Approach to study a topic from the immediate environment in depth, curriculum standards are met in an integrated way, rather than through segmented subject areas. The benefits of project according to Hyson (2008), under the right environmental conditions, many young children can "pick up" the names of colors and shapes and need little in the way of didactic or systematic formal instruction to learn them.

\subsection{The intervening variables}

According to Heffner (2014) intervening variables are underlying abstract processes that are not directly observable but that link the independent and dependent variables. This article was cognizant to the fact that apart from the learning strategies, other underlying factors would likely impact on reading proficiency. These includes the environment and the support from the administration.

\subsubsection{The Environmental features}

For effective learning experiences to take place the learning environment has to be modified to motivate the experiences. It is imperative that early reading is supported by settings that sustain pre-reading activities, skills and strategies. The branched root to the left represents environmental features necessary for early (emergent) 
reading. Emergent reading strategies must be supported by literacy rich structures which offer materials and activities throughout the classroom that encourage reading and talking (Lindberg and Swedlow (1976). To teach reading effectively, the environment needs to be modified such that it taps into children's individual interests, draw out their emerging reading capacities, and responds to their sense of inquiry and exploration.

Roskos (2003) had this to say, "To motivate and engage students, teachers must create a classroom environment in which every student comes to believe, 'I count, I care, and I can". To teach reading effectively, the environment needs to be modified such that it taps into children's individual interests, draw out their emerging reading capacities, and responds to their sense of inquiry and exploration. Helping children to enjoy reading is one of the most important things adults can do. In most cases children come to associate the kind of reading taught in school with work, not pleasure. As a result, they lose their desire to read. And it is that desire- the curiosity and interest- that is the cornerstone to using reading and related skills successfully.

It is important for ECDE teachers to create a classroom climate in which children develop an appreciation of literature and to stimulate children to read. The arrangement of the books and the arrangement of space for reading or for story telling are important factors to be considered in setting up a room for children (Lindberg and Swedlow, 1976). ECDE teachers are strongly encouraged to provide literacy-rich environments that enhance children's natural responses of curiosity, exploration and communication. Stroud (1995) avers that literacy-rich activities and environment offers literacy-related benefits of helping children understand symbolization refine visual discrimination develop fine motor coordination and practice oral language skills.

Therefore carefully designed environments should feature structures, objects, props, and labels. This would include a library corner, Games and puzzles, letter blocks, signs and printed directions, labelled classroom furniture and equipment, wall displays, signs, printed directions and displays of children's work made on the walls and in places that count. Straud (1995) was certain that using literacy for real purposes provides a purpose for its use and helps children become aware of the role of print in their daily lives.

According to Moor (2002) in appropriate learning spaces children can observe the various play possibilities and move in/out of the spaces at ease. The teacher should, therefore, provide an environment that has interesting materials and equipment, so that the children are stimulated in their engagement in activities that support emergent reading. These way pupils will perform or do a hands-on, minds-on experience with little or no help from the teacher. This might include making models, role playing, creative activities and other related activities that are foundational for reading.

\subsubsection{Administrative provisions}

Another factor considered in this model is administrative provision that support utilization of learning experiences. In the model, the root to the right stands for the support from the school administration that enables experiential strategies. The model is appreciates the fact that efforts to enhance teacher effectiveness revolve around the support mechanisms in place. Efficiency is not a one man's show. It is a collective responsibility. This calls for the school administration to fully take up its role which is to ensure that the school has all the right human and material resources necessary for stimulating the child's reading. To do this effectively the ECDE manager should martial up support from parents and all other stakeholders in availing the right quality and quantity of resources. All these would require a very supportive school administration that is ready to provide these materials. A good early childhood setting will require plenty of money and the school must be ready to prioritize the acquisition of the necessary equipment and materials.

\subsection{The moderating variables}

Heffner (2014) defines a moderator variable as a third variable that affects the strength of the relationship between a depended and independent Variable. Just above the roots (Figure 1) are the weeds which signify the moderating variables. Even though weeds are troublesome in the crop yield, they also have their usefulness to plants. In this model, moderating variables include teachers' characteristics such as creativity, teacher's mood, and skills in handling a reading lesson, teacher's knowledge of content; and instructional process factors which include the range of activities, time allocated for the activities, flexibility of students and statement of clear goals.

For any 21 st century teacher, creativity is critical for successful classroom processes. Children enter school boiling over with eagerness in wanting to read. Teachers need to be creative in teaching early reading in the way they use experience stories, listening and seeing games, dramatizations, telling original stories and reciting poems among others, so as to bring forth children's capabilities from within the children. Additionally, the mood 
of the teacher can affect how they learn to read. When the teacher comes into the classroom barking at the children and showing disapproval, the children may react in the same way and this can have a significant impact on their enthusiasm for learning. Further, teachers will need to be enthusiastic and motivated enough to work with children. In addition to being prepared for teaching young children, teachers need to adjust their disposition to behave in certain ways, to be able to work well with children. It is necessary that they are grounded in knowledge of content, in communication skills and in dealing with children and to be enthusiastic enough to rub on their learners because enthusiasm is contagious. This will create greater interest for reading and more importantly translate to improved reading competence at later levels

What's more, teachers need to possess a body of knowledge about reading. They should understand how texts are organized, which concepts and vocabulary are critical and how to evaluate key ideas in early reading. They should be knowledgeable about reading development and know why learners may experience difficulties in learning to read. In essence, they should exhibit expertise in designing lessons that promote reading.

Instructional process factors can also affect how children learn to read. For instance, clarity of the goals for a reading lesson may hinder learners from learning to read. Stating the objectives that the reading lesson intends to achieve helps learners to focus on what the teacher wants them to learn. In line with the objectives, teachers should provide feedback to learners because this tells learners whether they are doing the right thing or that they should modify their learning. It also is important for the child to love reading and therefore they should be given many opportunities to develop pre-reading and reading skills. This points to the fact that reading processes are very crucial in teaching reading.

\subsection{The dependent variable (Proficiency in reading)}

In the model, the fruits stand for the final product or the expected learning outcomes. The fruits symbolize fluency in reading. Fluency is defined as the ability to read with speed, accuracy and proper expression. Good quality fruits come as a result of good quality roots. Good quality fruits look attractive, have good flavor and have more nutritive value. This is exhibited in the form of superior diction, good articulation, improved ability to identify words, reading at the right speed and the realization of reading power. Literate children should: read and write with confidence, fluency and understanding; be interested in books, read with enjoyment and evaluate and justify their preferences; be able to orchestrate a full range of reading cues (phonic, graphic, syntactic, contextual) to monitor and self-correct their own reading; have an interest in words and word meanings, and a growing vocabulary; understand the sound and spelling system and use this to read and spell accurately. Emergent literacy experiences that are well structured and effectively applied will create greater interest for reading and more importantly translate to improved reading competence at later levels. This will create greater interest for reading and more outstandingly translate to improved reading competence at later levels in the form of superior diction, good articulation, improved ability to identify words, reading at the right speed and the mastery of reading power.

\section{$4 \quad$ Relevance of the model}

It is common knowledge to educators that a student learns more quickly and retains more information when the subject matter pertains to them personally. The process of experiential learning involves both self-initiated and self-assessment, as well as hands-on activity. Therefore emergent reading programs must focus on learning strategy which involves individualized hands-on activities in a manner that affords all children the opportunity to successfully acquire fluent reading skills. This model is even more relevant in today's world where the reading culture is at its lowest ebb, where the power of memory has been left to the mercy of technological gadgets and children can no longer commit knowledge into memory. Therefore children should experientially be exposed to opportunities that create interest in reading at the very onset of the reading continuum, at the emergent reading stage.

\section{Conclusion}

This article has articulated the fact that becoming competent readers early in life is a prerequisite for learning in all other areas and for achievement at later levels of children's learning. This effect was presented as model dubbed "The Ficus Model of Reading Development". In it reading development is symbolized by a ficus tree in which the quality of the fruits is determined by the strength of the roots. The main root stands for well utilized experiential strategies for teaching early reading. These strategies include learning through play, learning through graphic arts, Music and movement, encouraging learning through groups, promoting early reading 
through stories, drama and project work among other creative strategies. This should be reinforced by settings (branching roots) that facilitate reading experiences. This would include a library corner, labels, signs and printed directions in places that count for the children. Alphabet displays and displays of children's work should be made on the walls. The learning centres should be made cozy, inviting places. Additionally, administrative support mechanisms are fundamental in making emergent reading efficient. This calls for the school administration to avail the right quality and quantity of physical and financial resources. The result is children who develop into proficient readers in terms superior diction, good articulation, improved ability to identify words, reading at the right speed and the realization of reading power. This in turn propel children to improve their learning outcomes and improve their chances in the labour market.

\section{References}

Balwin, P. \& Fleming, K. (2012). Teaching Literacy Through Drama: Creative Approaches. Routledge pp 7-4: Amazon.com (Retrieved on 27/7/2014).

Bartsch, C (2013). Imporatnce of Hands-on experience in the elementary classroom

Bureau of Elementary Education (1994). The Multigrade Teacher's Handbook. The Philipins:Department of Education, Culture and Sports.

Crombie, M. (1997). The effects of Specific Learning difficulties (dyslexia) on learning of a foreign language in school. Dyslexia: An international Journal of Research and Prctice, 3(1). 27-47

Davidson, J. (1996). Emergent Literacy and Dramatic Play in Early Education. New York, New York: Delmar Publishers.

Dodd, A.W. (1994). Learning to read the classroom: The stages leading to teacher Self- Actualization. Northwords:4:13-26

Foley, E., et al. (2008).Beyond Test Scores: Leading Indicators for Education. Providence, RI: Brown University, Annenberg Institute for School Reform. Available for download at <www.annenberginstitute.org/WeDo/leading indicators.php>

Heffner,C.(2014). Retrieved from www.allpsych.com on $15^{\text {th }}$ August 2017

Hyson, M. (2008). Enthusiastic and Engaged Learners: Aprroaches to learning in the early childhood classroom. Michigam: Teachers College

Katz, L.G. (1994). The Project Approach. Eric Digest. Champaign. IL: ERIC clearinghouse on Elementary and Early Childhood Education ED 368 -509.

Kolb, D. A. (1984). Experiential learning: Experience as the source of learning and development. Englewood Cliffs, NJ: Prentice-Hall.

Lindberg, L. \& Swedlow, R.(1976). Early Childhood Education. Boston: Allyn and Bacon.

Miller,M.M \& Commons, M.L (1994). Emotional Learning in Infants: A Cross-Cultural Examination. Retrieved from www.naturalchild.org on 25 Sep 2017

Moor, G. (2002). Child care design guide. New York: McGraw-Hill

Muij, D. and Reynolds,D. (2001). Effective Teaching: Evidence and Practice. London: Paul Chapman publishing

Musen, L (2010) Early Reading Profiency. New York: Brown University

Nores, M and Bernet W.S. (2010). Benefits of Early Childhood Intervention Across the world. Economics of Education Review 29(2) 271-282.

Pascal, E.C. (1977). Teaching and Learning: an individualized course for instructors. Mc Gill: Centre for learning and development.

Rich D., Drummond,M.J., Myer, A \& Dixon, A. (2005). First Hand Experience: What matters to children. www.richlearningopportunities.co.ke. Retrieved on 12/9/2017.

Roskos,K.A. et al. (2003). The essentials of Early Literacy Instruction. YC: Young Children, 58(2),52-60

Roopnarine, J. and J.E. Johnson (2013). Approaches to Early Childhood Education. Merrii/Prentice Hall

Sandefur,S.J., Hicks,HK., Buck,J.A., Warren,A., \& Gamble, A (2006). Preschoolers' Understanding of Print. Unpublished assessment, University of Tennessee at Chattanooga.

Singer, D. and Singer, J. (2010). Children, Imagination, Play, and Television. Sacred Heart University Review: Vol. 16: Iss. 1 , Article 3.

Stroud, J.E. (1995). Block play: Building a foundation for literacy.Early Childhood Education Journal,23(1), 9-13.

Terenzi, P. T. \& Pascarella, E. T. (1994). Living With Myths, Undergraduate Education In America. Change, (26)1, 28-32.

UNESCO (2005). Policy Review Report: Early childhood Care and Education in Kenya. Paris: UNESCO

UNICEF (1999). Teachers Talking about learning. http:/www.unicef.org/teachers. Retrieved on 14/10.2018

Wigfield, A. (1997). Change in Children's Competency Beliefs and Subjective Task Values across the Elementary School Years: A 3-year Study. Journal of Educational Psychology 89, no. 3.

Wortham,S.C (2013). Assessment in Early Childhood Education: Pearson new International Edition< $<$ Pearson Higher Ed. 